УДК 130.2

$10.17213 / 2075-2067-2020-4-180-187$

\title{
МУЗЕЙ ИСТОРИИ ОБРАЗОВАТЕЛЬНОГО УЧРЕЖДЕНИЯ КАК ИНСТРУМЕНТ ФОРМИРОВАНИЯ ЭТНОКУЛЬТУРНОЙ И НАЦИОНАЛЬНОЙ ИДЕНТИЧНОСТИ СОВРЕМЕННОЙ МОЛОДЁЖИ
}

\author{
(C) 2020 г. И. А. Левандина*, Д. Ю. Шалков **
}

*Ростовский юридический институт МВД России, г. Ростов-на-Дону, Россия **Ростовский-на-Дону колледжс информатизации и управления,

\section{2. Ростов-на-Дону, Россия}

Цель исследования заключается в рассмотрении роли музея истории образовательного учреждения в патриотическом воспитании современной молодёэи, а также в формировании её этнокультурной и национальной идентичности.

Методология исследования базируется на принщипах трансдисциилинарной социально-философской теории и методах культурологического анализа.

Результаты. $B$ статье делается вывод о том, что подрастающее поколение с его тотальным погружением в мир виртуальной реальности зачастую отвергает традиционные, классические формы построения образовательного процесса в пользу интерактивных моделей усвоения компетенций и обмена информацией. В этих условиях музейные и историкоархитектурные комплексы, природные заповедники предоставляют уникальную возможность сохранить историческую память нации и освоить многовековой культурно-эстетический опыт. Авторы приходят к выводу о том, что важнейшим аспектом в воспитании молодёжи является музейная деятельность образовательных учреждений и развитие их сотрудничества с региональными музеями.

Перспективы использования результатов. Существует прямая связь между отношением студентов к учебному заведению, качеством профессиональной подготовки и усилением их патриотических настроений. Знание обучающимися истории образовательной организации способствует улучшению мотивации к учёбе и повышению качества успеваемости, формирует адекватную самооченку будущего специалиста и его активную гражданскую позищию.

Ключевые слова: музей истории образовательного учреждения; этнокультурная и национальная идентичность; культурно-исторический код; современная молодёжь; патриотическое воспитание.

\section{MUSEUM OF THE HISTORY OF AN EDUCATIONAL INSTITUTION AS A TOOL FOR FORMING THE ETHNO-CULTURAL AND NATIONAL IDENTITY OF MODERN YOUTH}

\author{
(C) 2020 I. A. Levandina*, D. Yu. Shalkov**
}

\footnotetext{
*Rostov Law Institute of the Ministry of Internal Affairs of Russia, Rostov-on-Don, Russia **Rostov-on-Don College of Informatization and Management, Rostov-on-Don, Russia
} 
The purpose of the research is to consider the role of the Museum of history of an educational institution in the Patriotic education of modern youth, as well as in the formation of its ethnocultural and national identity.

The research methodology is based on the principles of transdisciplinary socio-philosophical theory and methods of cultural analysis.

Results. The article concludes that the younger generation with its total immersion in the world of virtual reality often rejects traditional, classical forms of building the educational process in favor of interactive models of learning competencies and information exchange. In these conditions, Museum and historical and architectural complexes, nature reserves provide a unique opportunity to preserve the historical memory of the nation and master the centuries-old cultural and aesthetic experience. The authors conclude that the most important aspect of youth education is the Museum activity of educational institutions and the development of their cooperation with regional museums.

Prospects for using the results. There is a direct link between the attitude of students to the educational institution, the quality of professional training and the strengthening of their Patriotic moods. Students ' knowledge of the history of an educational organization helps to increase motivation to study and improve the quality of academic performance, forms an adequate selfassessment of the future specialist and his active civic position.

Key words: museum of the history of an educational institution; ethno-cultural and national identity; cultural and historical code; modern youth; patriotic education.

Введение. В современной ситуации социального бытия наблюдается устойчивое углубление процессов отчуждения человека, критической формы его социального перерождения, которая принимает поистине глобальные масштабы, связанные прежде всего с потерей жизненных идеалов, морально-этических ориентиров и нравственных ценностей. Одновременно обостряются и противоположные отчуждению процессы формирования этнокультурной и национальной идентичности. В мировом масштабе это выражается в форме глобализации, борьбы стран за суверенитет и сохранения национальной безопасности.

Особенно остро эти процессы проявляются в молодёжной среде, которая не получила от старшего поколения должным образом оформленного представления об историческом наследии предков, прочной системы истинных ценностей, в отличие от материальных псевдоценностей эпохи массового потребления. Современные исследователи подчёркивают, что «обострённый индивидуализм, релятивизм и нигилизм с каждым годом всё прочнее входят в сознание нашей молодёжи - это продукт постсоветского образования и свободного доступа к массовой культуре. В новой России уже целое поколение молодёжи социализировалось в условиях духовно-нравственного дефицита, свободы от моральных устоев и направленности на материальное благосостояние...» [12].

Очевидно, что особенно пристальное внимание следует уделять трудовому и патриотическому воспитанию подрастающего поколения, для того чтобы в России стали принципиально невозможными сомнения в непреходящих национальных ценностях русского народа, пересмотр итогов Великой Отечественной войны, появление нацистских организаций, потеря интереса к отечественной истории и гордости за свою страну [15].

Существует множество путей выхода из этой ситуации. Один из них - возрождение интереса к культурному наследию России, а именно всех народов, живущих на её территории, популяризация и государственная поддержка внутреннего молодёжного туризма. Кроме того, современное подрастающее поколение с его тотальным погружением в виртуальную реальность социальных сетей и мессенджеров всё легче воспринимает интерактивные формы построения образовательного процесса, в отличие от традиционных, классических моделей, 
что вовсе не означает необходимости повсеместного отказа от них.

Результаты исследования. Российские региональные музеи, подобные Старочеркасскому историко-архитектурному музею-заповеднику, обеспечивают эффект присутствия, позволяют физически ощутить ту среду, в которой жили наши предки. Крайне важную роль в этом отношении приобретают этнографические, фольклорные праздники [9], исторические реконструкции, культурно-образовательные квесты [14], фестивали ремёсел, мероприятия и торжества, приуроченные к памятным датам, которые связаны с важнейшими вехами российской истории и культуры (в частности, проводимые в 2020 году онлайн-выставка «Широка страна моя родная» в рамках празднования Дня России, онлайн-экскурсия «Я живу в России», посвящённая станице Старочеркасской) [1], и многое другое. Не менее важное значение имеет привлечение учащейся молодёжи к музейной работе - архивной, поисковой, научно-исследовательской, археологической, организационно-методической [8]. Музейные комплексы нашей страны - это культурно-исторический национальный код территории Российской Федерации. Поддержка, развитие и расширение музеев - задача государственная, системная, стратегическая.

Обязанность современной молодёжи не просто сохранить для потомков наследие наших предков, но и передать регионоведческую информацию о быте и традициях сегодняшнего поколения [4]. Эта информация кажется предельно очевидной только с позиции нынешнего времени и обретает глубинные смыслы в долгосрочной исторической перспективе. Россия имеет самую большую в мире территорию и самое богатое культурное наследие, нуждающееся в бережном сохранении и популяризации. Важнейшей миссией музейной работы в нашей стране является развитие внутренних туристических потоков, что особенно актуально в условиях пандемии.

Пожалуй, самым главным достоянием страны являются её граждане. Это те, к сожалению, немногочисленные энтузиасты, которые бескорыстно и самозабвенно готовы делиться своим талантом и творческими идеями. Именно на их инициативе и знаниях держится передача культурного наследия от поколения к поколению. Только искренность и неподдельный патриотизм способны проникнуть в души современного «киберпоколения» [13]. Природные заповедники, музейные и историко-архитектурные комплексы предоставляют уникальную возможность освоить культурно-эстетический опыт, получить незабываемые впечатления и яркие эмоции.

Донская земля необычайно богата культурным наследием предков. Однако существуют проблемы самопрезентации и отсутствия единой стратегической концепции сохранения и развития культурного развития региона. К сожалению, нынешние реалии не оставляют времени на промедление. Биполярный мир в очередной раз ставит перед человечеством выбор между добром и злом, знанием и невежеством, культурой и варварством. Какой выбор сделает нынешняя молодёжь, зависит не только от педагогического сообщества, деятелей культуры и искусства, но и от каждого нас.

Ещё одним важным аспектом в воспитании молодёжи является музейная деятельность образовательных учреждений. Очевидно, что существует неразрывная связь между отношением студентов к учебному заведению, качеством профессиональной подготовки и усилением их патриотических настроений. Знание обучающимися истории своей образовательной организации способствует улучшению мотивации к учёбе и повышению успеваемости, формирует адекватную самооценку будущего специалиста и его активную гражданскую позицию [3], многократно повышает уровень его внутренней культуры и патриотизма [15], создаёт представление о позиционировании на рынке труда после окончания учебного заведения и об уникальности территории, где предстоит осуществлять будущую профессиональную деятельность. Ощутимый эффект возникает при непосредственном участии студентов в создании музея истории учебного заведения. В этот процесс входит сбор материалов, их систематизация и оформление, помощь в работе руководителя музея.

В ГБПОУ РО «Ростовский-на-Дону колледж информатизации и управления» к 65-лет- 
нему юбилею был открыт музей истории колледжа. Созданию музея колледжа предшествовал долгий и кропотливый труд по сбору информации, материалов и экспонатов [7]. Основой экспозиции музея стала зародившаяся в середине 60-х годов прошлого века традиция составлять альбомы-летописи каждой группы и оставлять их на память колледжу. Более того, с 1983 года группа «Поиск» вела поисковую работу о боевой истории героической 240-й стрелковой дивизии. По результатам исследований была открыта комната боевой славы. Материалы, собранные преподавателями и студентами, переписка с ветеранами войны сохранились и стали первыми экспонатами музея истории колледжа.

Активное участие в организации принимали студенческий совет и выпускники юбилейного 2009 года. Собирая материалы для экспозиций, опрашивая преподавателей, которые много лет трудились в колледже, студенты узнают много интересных фактов. Среди них и то, что первоначально у техникума не было собственного здания, ведь в дважды оккупированном, практически разрушенном Ростове-на-Дону в ноябре 1944 года с помещениями было крайне тяжело; и то, что нынешние здания колледжа и общежития после занятий помогали строить преподаватели и студенты конца 60-х годов; и то, что с начала 70-х по конец 80-х годов прошлого века в тогда ещё техникуме механизации учёта учились студенты из 25 стран мира.

За 75 лет существования колледжа его возглавляли 9 директоров, двое из которых руководили в общей сложности 32 года: А.А. Третникова с 1962 по 1979 год и Н.В. Толстик с 1994 по 2009 год. Около 50 лет в колледже проработали преподаватель информационно-коммуникационных технологий Н. Г. Коновалова, 38 лет - последний директор колледжа, кандидат педагогических наук, доцент кафедры информационных технологий, заслуженный учитель РФ, почётный работник среднего профессионального образования В.И. Невзорова, 38 лет - преподаватель Л.Н. Чечевицына, 33 года - преподаватель Г.Б. Казначевская.

И это без преувеличения труд, достойный самых высоких наград, пример для студентов и молодых педагогов ответственного и самоотверженного отношения к своему делу. По словам В.И. Невзоровой, достижения преподавателей и студентов колледжа, «отличные успехи в учебной деятельности, плодотворное участие в исследовательской работе» обусловлены «активной жизненной позицией» - «среди преподавателей есть кандидаты наук, победители областного конкурса «Педагогический работник в системе профессионального образования» в различных номинациях и лауреаты конкурсов всероссийского уровня» [10].

Так, 7 января 2016 года в музее истории колледжа состоялась встреча первого выпуска программистов 1975 года. 40-летие выпуска отметили бывшие студенты во главе с классным руководителем Л.А. Комардиной в канун её 80-летия. Ровно 51 год Людмила Алексеевна преподавала математику. Много поколений выпускников вспоминают о ней с особым трепетом и теплотой. В сентябре 2017 года Людмилы Алексеевны не стало, но все учителя живы до тех пор, пока о них помнят благодарные выпускники. Точно так же жива национальная идентичность, пока люди посещают музеи и интересуются историей во всех её проявлениях - от своего собственного родословного древа до летописи стран и народов.

В настоящее время отношение к труду коренным образом изменилось, причём не в лучшую сторону. На это есть объективные и субъективные причины: рыночные механизмы взаимодействия, новый тип общественных отношений, инновационные формы интеллектуальной деятельности, общее снижение уровня культуры, в том числе и языковой [6], девальвация моральных и нравственных ценностей, неуверенность в завтрашнем дне, усложнение характера труда, его интенсивности и многое другое.

Очевидно, что современное подрастающее поколение является свидетелями формирования нового типа специалиста с новыми качествами и новыми компетенциями. Музей истории организации имеет не только воспитательное, но и образовательное значение. Так, например, учебная дисциплина «Технология» может отдельной темой включать историю учебного заведения. На базе музея может быть организована регулярная внеурочная деятельность [2], активная поисковая работа по пополнению фонда музея, 
переписка с ветеранами и выпускниками колледжа, могут проводиться внеклассные мероприятия.

Кроме того, музей истории колледжа может стать базой для научной, проектной работы преподавателей и студентов [5], творческой деятельности по передаче передового педагогического опыта [1], площадкой для встреч выпускников и сотрудников колледжа. Все эти работы проводились в течение 10 лет существования музея колледжа. Сегодня, в 2019-2020 учебном году, ГБПОУ РО «Ростовский-на-Дону колледж информатизации и управления», отметив 75-летие, находится в процессе реорганизации в форме присоединения к ГБПОУ РО «Ростовский-на-Дону колледж связи и информатики» «в целях оптимизации, ... приведения объёмов и структуры подготовки рабочих (служащих) и специалистов среднего звена в соответствие с потребностями регионального рынка труда, повышения эффективности использования материально-технических, финансовых и кадровых ресурсов образовательных организаций» [11]. Этот процесс означает, что колледж информатизации и управления сам становится историей, органично вписанной в историю области и страны.

Заключение. Учитывая исключительную научную и практическую значимость музея истории образовательной организации, стремительно меняющиеся условия деятельности и необходимость грамотного выстраивания стратегии патриотического воспитания молодёжи, представляется актуальным создание и развитие организационной структуры музеев указанного типа, развитие сотрудничества с музеями Дона. Позитивный пример такого сотрудничества - совместная работа со Старочеркасским историко-архитектурным музеем-заповедником, сотрудники которого являются выпускниками Ростовского-на-Дону колледжа информатизации и управления, а именно: выездные выставки, стажировки преподавателей, их участие в организации научно-практических конференций, экскурсионных маршрутов, производственной практики студентов на базе музея-заповедника, а также рецензирование рабочих программ учебных дисциплин, учебно-методических комплексов и фондов оценочных средств. Разнообразные формы деятельности способствуют формированию этнокультурной и национальной идентичности донской молодёжи, интенсифицируют патриотический компонент воспитательной работы.

\section{Литература}

1. Андреева И.Н., Константинова В. В. Музейная педагогика в контексте этнокультурной подготовки будущих педагогов // Вестник Марийского государственного университета. 2017. - T. 11. — №3(27). - С. 13-19.

2. Володина Л.И. Музейная педагогика как структурный элемент внеурочной деятельности // Образование в современной школе. - 2013. - №2. - С. 62-64.

3. Колмакова В.В. Определение уровня сформированности активной гражданской позиции современного студента // Филологические науки. Вопросы теории и практики. Тамбов, 2016. — №10-3 (64). — С. 182-186.

4. Колмакова В.В. Регионоведческая информация как составляющая содержания образования // Межнациональные отношения в Ростовской области: история, современное состояние, практики регулирования и перспективы: материалы научно-практической конференции. - Ростов н/Д, 2016. C. 114-120.

5. Колмакова В. В., Шалков Д. Ю. Технология проектов в современном образовательном пространстве // Преподаватель высшей школы в XXI веке: труды 12-й Международной научно-практической Интернет-конференции. - Ростов н/Д: РГУПС, 2015. Сб. 12. - С. 231-238.

6. Колмакова В. В., Шалков Д. Ю. Особенности русского коммуникативного поведения в начале XXI века // Вестник Пятигорского государственного университета. - Пятигорск: ПГУ, 2018. — №4. - С. 61-64.

7. Левандина И.А., Левандина С.Д. Роль музея истории колледжа в сохранении традиций и культурного кода организации // Вестник Старочеркасского историко-литературного музея-заповедника. - 2017. Вып. 5. - С. 42-44.

8. Мотина В. В. Культурно-образовательная деятельность музеев и музейная педагогика // Труды Санкт-Петербургского госу- 
дарственного университета культуры и искусств. - 2013. - Т. 195. - С. 307-310.

9. Нагайцева Н.Д., Гусейнова Т.Н. Музейная педагогика: музейные праздники. Технология подготовки и проведения: учеб. пособие для студ. высш. учеб. заведений, обучающихся по специальностям 070503 «Музейное дело и охрана памятников» и 031502 «Музеология». - Улан-Удэ: ФГОУ ВПО «Восточно-Сибирская гос. акад. культуры и искусств», 2005. - Ч. 2. - 59 с.

10. Невзорова В. И. «В учебном процессе мы широкомасштабно используем информационные технологии» // Парламентский вестник Дона. - 2015. - №18 (90). [Электронный ресурс]. - Режим доступа: http://www.vestnikdona.ru/article/kultura/18 90noyabr2015VeraNevzorovaVuchebnompr otsessemyshirokomasshtabnoispolzueminfo rmatsionnyetekhnologii/. (Дата обращения: 03.07.2020 г.).

11. Постановление Правительства Ростовской области №907 «О реорганизации государственных бюджетных образовательных учреждений Ростовской области» от 9 декабря 2019 г. [Электронный ресурс]. — Режим доступа: https://www.donland.ru/documents/11065/. (Дата обращения: 03.07.2020 г.).

12. Романенко П.В. Философия, музейная педагогика и практика музея: интеграция в условиях социокультурных трансформаций // Социальные трансформации. 2013. - №23. - C. 139-145.

13. Федулова Е.С., Федулов С.П. Роль и место музейной педагогики в формировании мировоззрения современных детей и молодёжи // Труды молодых учёных: сборник материалов и докладов. - М.: Московский государственный областной гуманитарный институт, 2012. - С. 181-184.

14. Шалков Д. Ю., Колмакова В.В. Технология квеста как эффективный способ формирования ассоциативного мышления обучающихся // Преподаватель высшей школы в XXI веке: труды 13-й Международной научно-практической Интернет-конференции. Ростов н/Д: РГУПС, 2016. - Сб.13. С. 287-296.

15. Шпенглер T.В. Музейная педагогика как эффективное средство воспитания патриотов // ВНЕшкольник. - 2008. №1 (124). - С. 16-18.

\section{References}

1. Andreeva I. N., Konstantinova V.V. Muzejnaja pedagogika $\mathrm{v}$ kontekste jetnokul'turnoj podgotovki budushhih pedagogov [Museum pedagogy in the context of ethnocultural training of future teachers] // Vestnik Marijskogo gosudarstvennogo universiteta [Bulletin of the Mari State University]. - 2017. — Vol. 11. №3 (27). - Pp. 13-19.

2. Volodina L.I. Muzejnaja pedagogika kak strukturnyj jelement vneurochnoj dejatel'nosti [Museum pedagogy as a structural element of extracurricular activities] // Obrazovanie v sovremennoj shkole [Education in a modern school]. - 2013. - №2. - Pp. 62-64.

3. Kolmakova V.V. Opredelenie urovnja sformirovannosti aktivnoj grazhdanskoj pozicii sovremennogo studenta [Determining the level of formation of an active civil position of a modern student] // Filologicheskie nauki. Voprosy teorii i praktiki [Philological Sciences. Questions of theory and practice]. - Tambov, 2016. — №10-3 (64). — Pp. 182-186.

4. Kolmakova V.V. Regionovedcheskaja informacija kak sostavljajushhaja soderzhanija obrazovanija [Regionological information as a component of the content of education] // Mezhnacional'nye otnoshenija v Rostovskoj oblasti: istorija, sovremennoe sostojanie, praktiki regulirovanija i perspektivy: materialy nauchnoprakticheskoj konferencii [International relations in the Rostov region: history, current state, regulation practices and perspectives: materials of the scientific and practical conference]. Rostov-on-Don, 2016. - Pp. 114-120.

5. Kolmakova V.V., Shalkov D. Ju. Tehnologija proektov V sovremennom obrazovatel'nom prostranstve [Technology of projects in the modern educational space] // Prepodavatel' vysshej shkoly v HHI veke: trudy 12-j Mezhdunarodnoj nauchno-prakticheskoj Internetkonferencii [Higher school teacher in the XXI century: proceedings of the 12th International scientific and practical Internet conference]. Rostov-on-Don: RGUPS, 2015. - Issue 12. Pp. 231-238.

6. Kolmakova V.V., Shalkov D. Ju. Osobennosti russkogo kommunikativnogo povedenija $\mathrm{v}$ nachale XXI veka [Features of Russian communicative behavior at the beginning of the XXI century] // Vestnik Pjatigorskogo 
gosudarstvennogo universiteta [Bulletin of Pyatigorsk State University]. - Pyatigorsk: PGU, 2018. - №4. - Pp. 61-64.

7. Levandina I.A., Levandina S.D. Rol' muzeja istorii kolledzha $\mathrm{v}$ sohranenii tradicij i kul'turnogo koda organizacii [The Role of the College history Museum in preserving the traditions and cultural code of the organization]// Vestnik Starocherkasskogo istoriko-literaturnogo muzeja-zapovednika [Bulletin of the Starocherkassk historical and literary Museumreserve]. - 2017. - Issue 5. - Pp. 42-44.

8. Motina $V . V$. Kul'turno-obrazovatel'naja dejatel'nost' muzeev i muzejnaja pedagogika [Cultural and educational activities of museums and Museum pedagogy] // Trudy SanktPeterburgskogo gosudarstvennogo universiteta kul'tury $\mathrm{i}$ iskusstv [Proceedings of the Saint Petersburg State University of Culture and Arts]. — 2013. - Vol. 195. - Pp. 307-310.

9. Nagajceva N.D., Gusejnova T.N. Muzejnaja pedagogika: muzejnye prazdniki. Tehnologija podgotovki i provedenija: ucheb. posobie dlja stud. vyssh. ucheb. zavedenij, obuchajushhihsja po special'nostjam 070503 «Muzejnoe delo i ohrana pamjatnikov» i 031502 «Muzeologija» [Museum pedagogy: Museum holidays. Technology of preparation and conducting: studies. student's guide. no. studies'. institutions that are trained in the specialties 070503 «Museum management and protection of monuments» and 031502 «Museology»]. - Ulan-Ude: FGOU VPO «Vostochno-Sibirskaja gos. akad. kul'tury i iskusstv», 2005. - Part 2. - 59 p.

10. Nevzorova V.I. «V uchebnom processe my shirokomasshtabno ispol'zuem informacionnye tehnologii» [«In the educational process, we use information technologies on a large scale»]// Parlamentskij vestnik Dona [Parliamentary Bulletin of the Don]. - 2015. - №18 (90). [Jelektronnyj resurs]. - URL: http://www. vestnikdona.ru/article/kultura/1890noyabr2015 VeraNevzorovaVuchebnomprotsessemyshiroko masshtabnoispolzueminformatsionnyetekhnolo gii/. (Date accessed: 03.07.2020).
11. Postanovlenie Pravitel'stva Rostovskoj oblasti №907 «O reorganizacii gosudarstvennyh bjudzhetnyh obrazovatel'nyh uchrezhdenij Rostovskoj oblasti» ot 9 dekabrja 2019 g. [Resolution of the government of the Rostov region №907 «On the reorganization of state budgetary educational institutions of the Rostov region» dated December 9, 2019] [Jelektronnyj resurs]. — URL: https://www.donland.ru/ documents/11065/. (Date accessed: 03.07.2020).

12. Romanenko P.V. Filosofija, muzejnaja pedagogika i praktika muzeja: integracija $\mathrm{v}$ uslovijah sociokul'turnyh transformacij [Philosophy, Museum pedagogy and practice of the museum: integration in the conditions of socio-cultural transformations] // Social'nye transformacii [Social transformations]. 2013. - №23. - Pp. 139-145.

13. Fedulova E.S., Fedulov S.P. Rol' i mesto muzejnoj pedagogiki $\mathrm{V}$ formirovanii mirovozzrenija sovremennyh detej i molodjozhi [The Role and place of Museum pedagogy in shaping the worldview of modern children and youth] // Trudy molodyh uchjonyh: sbornik materialov i dokladov [Proceedings of young scientists: collection of materials and reports]. Moscow: Moskovskij gosudarstvennyj oblastnoj gumanitarnyj institut, 2012. - Pp. 181-184.

14. Shalkov D. Ju., Kolmakova V.V. Tehnologija kvesta kak jeffektivnyj sposob formirovanija associativnogo myshlenija obuchajushhihsja [Quest Technology as an effective way of forming students' associative thinking] // Prepodavatel' vysshej shkoly v XXI veke: trudy 13-j Mezhdunarodnoj nauchnoprakticheskoj Internet-konferencii [Teacher of higher education in the XXI century: proceedings of the 13th International scientific and practical Internet conference]. - Rostov-on-Don: RGUPS, 2016. - Issue 13. - Pp. 287-296.

15. Shpengler T.V. Muzejnaja pedagogika kak jeffektivnoe sredstvo vospitanija patriotov [Museum pedagogy as an effective means of educating patriots] // VNEshkol'nik. — 2008. №1 (124). - - Pp. 16-18. 


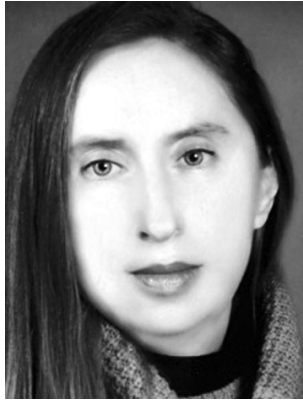

Левандина Ирина Алексеевна - кандидат философских наук, доцент кафедры гуманитарных и социально-экономических наук Ростовского юридического института МВД России.

Levandina Irina Alexeevna - Candidate of Philosophical Sciences, Associate Professor, Department of Humanities and Socioeconomic Sciences, Rostov Law Institute of the Ministry of Internal Affairs of Russia.

344015, г. Ростов-на-Дону, ул. Еременко, 83

83 Eremenko st., 344015, Rostov-on-Don, Russia

E-mail: levandina@rgkiu.ru

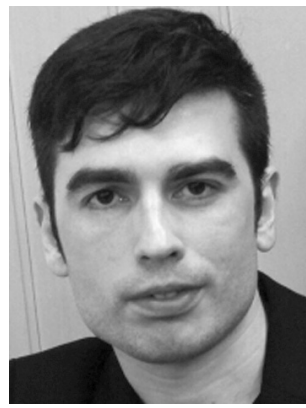

Шалков Денис Юрьевич - кандидат филологических наук, Ростовский-на-Дону колледж информатизации и управления.

Shalkov Denis Yurievich - Candidate of Philological Sciences, Rostov-on-Don College of Informatization and Management.

344058, г. Ростов-на-Дону, пр. Коммунистический, 11

11 Kommunisticheskiy ln., 344058, Rostov-on-Don, Russia

E-mail: shalkovdenis@yandex.ru 